\title{
Allozyme genetics, self-incompatibility and male sterility in Plantago lanceolata*
}

\author{
Henk van Dijk
}

\author{
Department of Genetics, Biology Center, University of \\ Groningen, Kerklaan 30, 9751 NN Haren, \\ The Netherlands.
}

In Plantago lanceolata 14 out of 39 enzyme loci showed genetic variation, as checked by analysis of crosses. Five linkage groups could be formed with these variable loci. They may represent five different chromosomes as $n=6$ in this species. The SI locus, controlling self-incompatibility, appeared to be very tightly linked with $P$ gm-1 (recombination $=$ 0.8 per cent) and somewhat more loosely with $6 \mathrm{Pgd}-1$ and $6 \mathrm{Pgd}-2$. In this linkage group also a recessive male sterility locus could be placed. A different male sterility locus with recessive effect was located in a second linkage group, and a male sterility locus with dominant effect in a third one.

These results, and the finding of differences in germination behaviour when certain chromosomes are substituted, point to the possible further use of allozyme loci in analysing the genetic basis of ecologically important differences in P. lanceolata.

\section{INTRODUCTION}

Allozyme variation has proved to be a successful tool in the analysis of genetic variation for ecologically important characters within the species Plantago major (Van Dijk, 1984). Although Plantago lanceolata shows less tendency to ecotypic differentiation, still many interesting examples of genetic variability have been reported: genetic variation for flowering time related to annual time of mowing and for leaf angle and length related to vegetation height has been found by Van der Toorn and Ten Hove (unpublished results). Genetic variation for seed yield is reported by Primack and Antonovics (1981); for photosynthetic response to temperature and irradiance by Teramura and Strain (1979). Sagar and Harper (1964) mention different varieties of $P$. lanceolata which also points to genetic differentiation.

Prior to the use of allozyme loci in analysing quantitative characters, their inheritance should be elucidated. Any linkage relations between the loci must be known. In the present study the inheritance of variable allozyme loci is investigated. Some other genetic differences which were met during these investigations are studied simultaneously:

\footnotetext{
* Grassland Species Research Group Publication No. 72.
}

those connected with the self-incompatibility system, with sex polymorphism and with germination behaviour. The genetics of self-incompatibility in P. lanceolata has been investigated by Ross (1973). Gynodioecy in this species has been studied recently by Van Damme (1983a) who succeeded in partially analysing its inheritance.

\section{MATERIALS AND METHODS}

Plantago lanceolata plants were collected at seven sites in the east $(\mathrm{Br}, \mathrm{He}, \mathrm{We}, \mathrm{Pa}, \mathrm{Ud})$ and the south-west ( Wd, Me) of the Netherlands, and were labelled according to origin and serial number. The sample size was about 100 per site. The plants were transferred to an experimental garden. Crosses were made in the greenhouse between plants which were different for many variable enzyme loci. The $F_{1}$ seeds were stored in a dry place for a few weeks and then germinated in petri dishes with wet filter paper. Seeds which did not germinate spontaneously were cut open at the side of the radicle. The seedlings were cultured in pots with soil and leaves were used for electrophoresis when the plants were four to six weeks old. After 
transplantation into the experimental garden the $F_{1}$ plants were scored for sex phenotype in the next summer. According to Van Damme (1983b) the sex phenotype was described as MS (male sterile), $\mathrm{H}$ (hermaphrodite), IN-a (predominantly male sterile), IN-b (intermediate), or IN-c (predominantly hermaphrodite).

Extract preparation, electrophoresis and subsequent staining were performed according to Van Dijk and Van Delden (1981). The best results were obtained with leaves of four to six week old seedlings from the greenhouse and with central leaves from winter-rosettes collected outdoors in winter or spring. Identical electrophoresis patterns were reached in both cases. Older leaves or leaves from plants growing under less optimal conditions needed more mercaptoethanol in the extract mixture to overcome their higher level of phenolic compounds.

Recombination frequencies between loci were calculated by a method which leads to approximately the same results as the maximum likelihood method (see Green, 1981) but which is easier when a computer is available. Advantages are that the 95 per cent intervals can directly be derived and that information about the relative likeliness of the segregation model is obtained if more than one model is possible. The method is based on the determination of the minimal $\chi^{2}$ value and will be described in Appendix A together with a worked example.
RESULTS

\section{Electrophoretic variation}

All plants collected in the field (about 700) were screened for electrophoretic variation. The same 21 enzyme systems as previously used for Plantago major (Van Dijk and Van Delden, 1981) were scored for $P$. lanceolata. In general the most probable number of loci derived from each enzyme staining pattern was the same as found in $P$. major, except for the enzymes Glyceraldehyde-3-phosphate dehydrogenase, Amylase and Esterase, where in each case one additional locus is postulated, bringing the most probable number of loci to 39. In two variable loci, Peroxidase-1 and Esterase-3, no clear genetic basis could be determined. Fourteen loci showed genetic variation as proved by crossing results. In table 1 the variable enzyme loci with their alleles are summarised together with other details. Allele frequencies in the sampled populations will not be given here, but form one of the subjects of a next paper (Van Dijk, Wolff and De Vries, in prep.).

Six plants from the populations $\mathrm{Br}, \mathrm{He}$ and $\mathrm{We}$ were selected for making crosses to verify the Mendelian inheritance of the allozyme loci. To detect linkage relations also $F_{2}$ 's were made by brothersister crossing within the $\mathrm{F}_{1}\left(\mathrm{He}_{88} \times \mathrm{We}_{44}\right)$. All crosses were made reciprocally. The allozyme genotypes of all plants used for these crosses could

Table 1 The variable enzyme loci

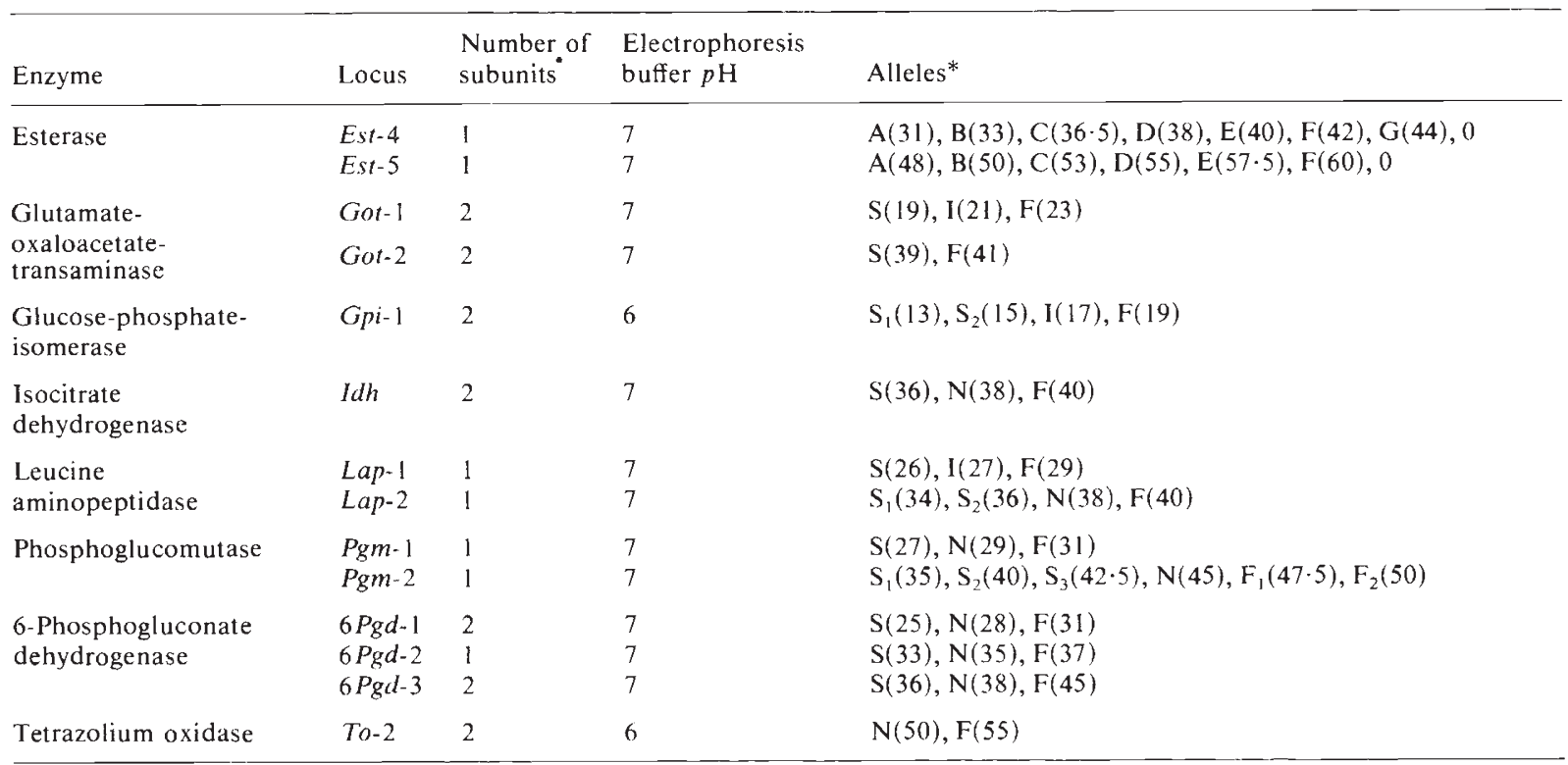

* $\mathrm{S}=$ slow, $\mathrm{N}=$ normal, $\mathrm{I}=$ intermediate, $\mathrm{F}=$ fast, $0=$ no activity. The esterase alleles are designated by other characters. The distances from the origin are given in parentheses (bromophenol blue $=100$ ). 
Table 2 Allozyme genotypes of the parent plants and of the $F_{1}$ plants used for making the $F_{2}$ 's

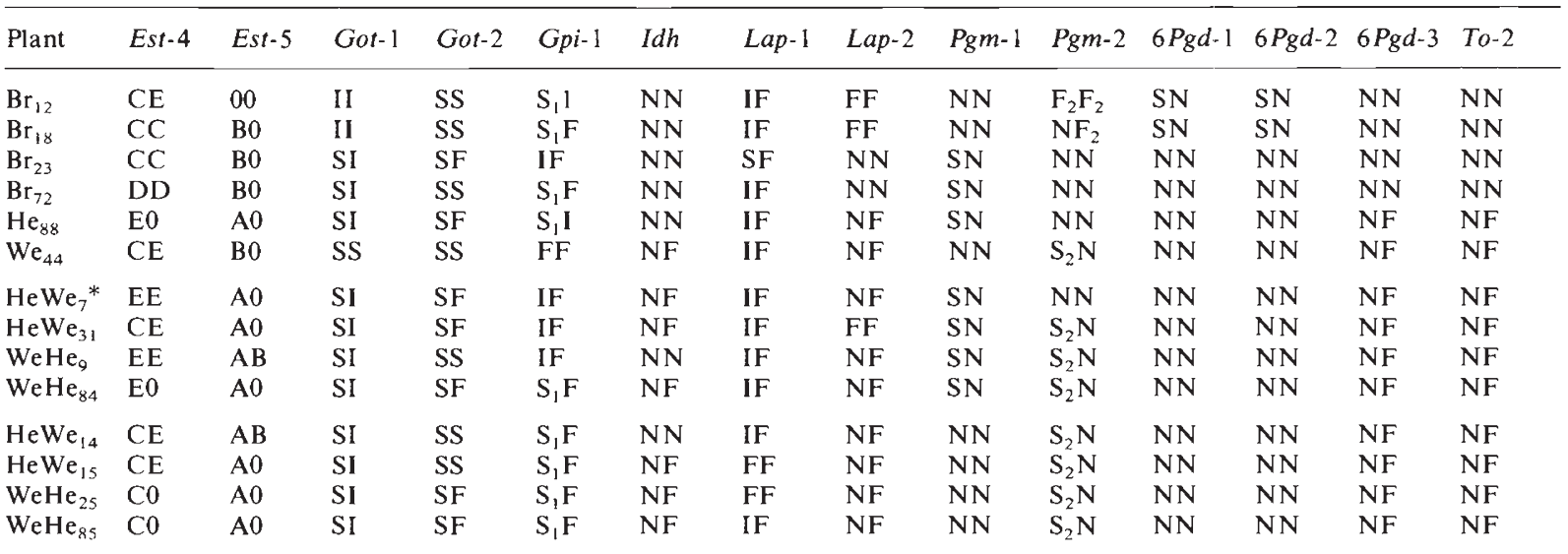

* The $\mathrm{F}_{1}$ plants derived from the cross $\mathrm{He}_{88} \rho \times \mathrm{We}_{44} \delta$ are designated as $\mathrm{HeWe}$; those from the reciprocal cross as WeHe.

be determined and are described in table 2 . The crosses are listed in table 3 . The variable allozyme loci were segregating in agreement with the expected ratios with three exceptions: Pgm-1, $6 P g d-1$ and $6 P g d-2$ showed strongly deviating ratios in particular crosses. In these cases the $S I$ locus, controlling self-incompatibility, is thought to be responsible for the deviations.

\section{The self-incompatibility locus}

Self-incompatibility in $P$. lanceolata is gametophytic: it is governed by one locus, the $S I$ locus, which prevents a plant from being fertilised by pollen carrying either of the two SI alleles present in the style (Ross, 1973). Self-fertilisation is thus made impossible, but also related plants will often be incompatible or half-compatible. The chance of unrelated plants not being fully compatible is believed to be low in general, because of the large numbers of $S I$ alleles usually present in natural populations.

In the $\mathrm{Br}$ population both $\mathrm{Br}_{12}$ and $\mathrm{Br}_{18}$ are carrying the same rare alleles of $6 P g d-1(\mathrm{~S})$ and 6Pgd-2 (S). $\mathrm{Br}_{23}$ and $\mathrm{Br}_{72}$ share a rare allele of Pgm-1 (S). These four plants were collected within a distance of $10 \mathrm{~m}$, so plants carrying an identical rare allele may be close relatives. When linkage exists between an enzyme locus and the $S I$ locus, the rare enzyme allele has a high chance of being linked with the same $S I$ allele in both parents, and will not be able to become homozygous without recombination. Any expected 1:2:1 ratio would change towards $0: 1: 1$, the exact ratio depending on the recombination frequency. Such ratios were indeed found for the crosses $6 P g d-1 \mathrm{SN} \times \mathrm{SN}$ and

Table 3 The crosses. Percentages of spontaneous germination and the number of segregating sex-phenotypes

\begin{tabular}{|c|c|c|c|c|c|c|c|c|c|c|c|c|}
\hline & \multirow[b]{2}{*}{$n$} & \multirow[b]{2}{*}{$\begin{array}{l}\text { Per cent } \\
\text { spontaneous } \\
\text { germination }\end{array}$} & \multicolumn{2}{|c|}{ Reciprocal cross } & \multicolumn{8}{|c|}{ Combined reciprocals scored for sex-phenotypes } \\
\hline & & & $n$ & $\begin{array}{l}\text { Per cent } \\
\text { spontaneous } \\
\text { germination }\end{array}$ & $n$ & MS & IN-a & IN-b & $1 \mathrm{~N}-\mathrm{c}$ & $\mathrm{H}$ & $\begin{array}{l}\text { Per } \\
\text { cent } \\
\text { MS }\end{array}$ & $\begin{array}{l}\text { Per } \\
\text { cent } \\
\text { IN }\end{array}$ \\
\hline $\mathrm{Br}_{12} \times \mathrm{Br}_{18}$ & 77 & 61 & 57 & 61 & 133 & 26 & 11 & 14 & 21 & 61 & $19 \cdot 5$ & $34 \cdot 6$ \\
\hline $\mathrm{Br}_{23} \times \mathrm{Br}_{72}$ & 90 & 57 & 44 & 57 & 133 & 0 & 0 & 0 & 0 & 133 & 0 & 0 \\
\hline $\mathrm{WeHe}_{84} \times \mathrm{WeHe}_{9}$ & 45 & 67 & 45 & 73 & 85 & 6 & 6 & 7 & 4 & 62 & $7 \cdot 1$ & $20 \cdot 0$ \\
\hline $\mathrm{HeWe}_{7} \times \mathrm{WeHe}_{9}$ & 45 & 51 & 45 & 51 & 79 & 9 & 4 & 4 & 5 & 57 & $11 \cdot 4$ & $16 \cdot 5$ \\
\hline $\mathrm{WeHe}_{25} \times \mathrm{HeWe}_{14}$ & 45 & 36 & 40 & 68 & $38^{*}$ & 5 & 0 & 3 & 0 & 30 & $13 \cdot 2$ & $7 \cdot 9$ \\
\hline $\mathrm{WeHe}_{85} \times \mathrm{HeWe}_{15}$ & 43 & 21 & 45 & 64 & - & & & & & & & \\
\hline $\mathrm{WeHe}_{25} \times \mathrm{HeWe}_{15}$ & 45 & 38 & 45 & 73 & - & & & & & & & \\
\hline
\end{tabular}

* Reciprocal cross not included. 
$6 P g d-2 \mathrm{SN} \times \mathrm{SN}\left(\mathrm{Br}_{12} \times \mathrm{Br}_{18}\right)$ and $P g m-1 \mathrm{SN} \times \mathrm{SN}$ $\left(\mathrm{Br}_{23} \times \mathrm{Br}_{72}\right)$.

The linkage of $P g m-1$ with the $S I$ locus was independently confirmed in the $\mathrm{F}_{1}$ of $\mathrm{He}_{88} \times \mathrm{We}_{44}$. The $\mathrm{F}_{1}$ plants with genotype $\mathrm{Pgm}-1^{\mathrm{SN}}$ contained two $S I$ genotypes $\left(\mathrm{HeWe}_{7}, \mathrm{HeWe}_{31}\right.$ and $\mathrm{WeHe}_{84}$ were not able to fertilise each other, but could be crossed with $\mathrm{WeHe}_{9}$ ) and the plants being Pgm$1^{\mathrm{NN}}$ behaved in the same way $\left(\mathrm{HeWe}_{14}\right.$ and $\mathrm{HeWe}_{15}$ belonged to one $S I$ type and $\mathrm{WeHe}_{25}$ and $\mathrm{WeHe}_{85}$ to the other). When crosses Pgm-1 SN $\times \mathrm{SN}$ succeeded they were half-compatible as could be concluded by the almost $0: 1: 1$ ratio of $\mathrm{SS}, \mathrm{SN}$ and $\mathrm{NN}$ in the progeny.

From the combined results for Pgm-1 (SS: $\mathrm{SN}: \mathrm{NN}=2: 227: 234)$ a recombination percentage of 0.8 (95 per cent confidence limits: 0.33.0 per cent) with the $S I$ locus could be calculated. The $6 P g d$ - 1 locus appeared to be somewhat more loosely linked with the $S I$ locus as established by the cross $\mathrm{Br}_{12} \times \mathrm{Br}_{18}$ and several backcrosses of $\mathrm{F}_{1}$ plants with $\mathrm{Br}_{12}$ (combined results: $\mathrm{SS}: \mathrm{SN}: \mathrm{NN}=$ $36: 581: 525)$ giving a recombination of 6.4 per cent $(4 \cdot 7-8 \cdot 8)$. As no recombination between $6 \mathrm{Pgd}$ 1 and $6 P g d-2$ could be detected, $6 P g d-2$ is at about the same distance to the $S I$ locus.

The expected linkage between $P g m-1$ and $6 P g d-1$ was qualitatively confirmed in an $F_{2}$ starting with the $6 P g d-1^{\mathrm{SS}}$ recombinant from the cross $\mathrm{Br}_{12} \times \mathrm{Br}_{18}$ and a $P g m-1^{\mathrm{SS}}$ recombinant from the cross $\mathrm{Br}_{23} \times \mathrm{Br}_{72}$. Unfortunately about 20 per cent non-viable albinos segregated in the $F_{2}$, making quantitative conclusions impossible. Also no sequence of the three loci $P g m-1,6 P g d-1$ and $S I$ could be established, as in the $F_{2}$ no recombinants between $P g m-1$ and $S I$ were found.

\section{Linkage groups}

In addition to the linkage data from the crosses $\mathrm{Br}_{12} \times \mathrm{Br}_{18}, \mathrm{Br}_{23} \times \mathrm{Br}_{72}$ and $\mathrm{H}_{88} \times \mathrm{We}_{44}$, the crosses between $F_{1}$ plants of the latter cross appeared to be very useful for linkage detection. Twelve loci were found segregating simultaneously in the $\mathrm{F}_{2}$ : all variable loci except for $6 P g d-1$ and $6 P g d-2$. Inbreeding effects like the occurrence of albinos mentioned in the previous section are met frequently in $P$. lanceolata, but appeared to be absent here: germination was almost complete and over 95 per cent of the progeny could be used for electrophoresis. In only one $F_{2}$ were the expected Mendelian ratios severely disturbed for the enzyme loci of one linkage group. Those results were discarded.

In table 4 the recombination percentages are summarised. Almost all other possibilities for link-
Table 4 Recombination percentages between enzyme loci, and their 95 per cent confidence intervals. $n=$ the combined progeny number

\begin{tabular}{clcl}
\hline $\begin{array}{l}\text { Linkage } \\
\text { group }\end{array}$ & Loci & $\begin{array}{l}\text { Recombination } \\
\text { percentage }\end{array}$ & $n$ \\
\hline I & Gpi-1-Lap-1 & $13 \cdot 5(11 \cdot 5-15 \cdot 8)$ & 924 \\
II & Got-1-Idh & $5 \cdot 3(3 \cdot 1-9 \cdot 0)$ & 452 \\
& Idh-Est-5 & $8 \cdot 4(5 \cdot 1-13 \cdot 1)$ & 650 \\
& Got-1-Est-5 & $12 \cdot 4(9 \cdot 7-15 \cdot 7)$ & 776 \\
III & To-2-Pgm-2 & $18 \cdot 6(16 \cdot 0-21 \cdot 7)$ & 742 \\
& Pgm-2-Est-4 & $30 \cdot 1(23 \cdot 2-38 \cdot 0)$ & 278 \\
& To-2-Est-4 & $39 \cdot 6(32 \cdot 0-47 \cdot 9)$ & 278 \\
IV & 6Pgd-3-Got-2 & $6 \cdot 1(4 \cdot 1-9 \cdot 0)$ & 733 \\
& Got-2-Lap-2 & $32 \cdot 3(27 \cdot 4-37 \cdot 5)$ & 646 \\
& $6 P g d-3-$ Lap-2 & $45 \cdot 0(40 \cdot 1-50 \cdot 0)$ & 734 \\
V & 6Pgd-1-6Pgd-2 & $0(0-1 \cdot 0)$ & 133 \\
\hline
\end{tabular}

age relations could be invalidated. The following survey of linkage groups with the sequence of the loci involved can now be made:

$$
\begin{aligned}
& \text { Linkage group I: Gpi-1Lap-1 } \\
& \text { II: Got-1--Idh---Est-5 }
\end{aligned}
$$

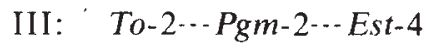

$$
\begin{aligned}
& \text { IV: } \quad 6 P g d-3-\text { Got-2--Lap-2 } \\
& \text { V: } 6 P g d-1 / 6 P g d-2 \cdots P g m-1 / S I
\end{aligned}
$$

These linkage groups may represent five different chromosomes as $n=6$ in this species.

The detailed outcome of the examination of the crosses, on which the results in table 4 are based, are not given in this paper but will be available on request.

\section{Male sterility}

Substantial numbers of male steriles (MS) and intermediate types (IN) were met in the population samples with percentages ranging from $1 \cdot 5$ to $18 \cdot 8$ for MS and from $3 \cdot 1$ to $30 \cdot 0$ for MS + IN. In some of the crosses male steriles and intermediates segregated too; in all cases plasmon type $R$ was involved (MSI and INI) as described by Van Damme and Van Delden (1982). Among the parents used, $\mathrm{Br}_{18}$, $\mathrm{Br}_{23}, \mathrm{Br}_{72}$ and $\mathrm{We}_{44}$ proved to be stable hermaphrodites, whereas $\mathrm{Br}_{12}$ and $\mathrm{He}_{88}$, although producing enough pollen to function as a male parent, could be considered as IN-c. The numbers of sex phenotypes appearing in each of the progenies are given in table 3 .

The inheritance of male sterility has been studied extensively by Van Damme (1983b), using plants of the Wd population. To be MSl, at least two recessive and three dominant genes should all be in the appropriate allelic state. He designated 
these male sterility loci in the $R$ plasmon type as $m r_{1}, \quad m r_{2}$ (recessives), $\mathbf{M r}_{3}, \quad \mathbf{M r}_{4}$ and $\boldsymbol{M} r_{5}$ (dominants). The same designation will be used here, without suggesting that the same subscript means the same locus in both studies. Intermediates INl were concluded by Van Damme to occur in an MS genotype by substitution of one arbitrary $m r^{\mathrm{mm}}$ by $m r^{\mathrm{m}+}$, and perhaps also by substitution of one arbitrary $\mathrm{Mr}^{\mathrm{M+}}$ by $\mathrm{Mr}^{++}$.

In the $\mathrm{F}_{1}$ resulting from $\mathrm{Br}_{12} \times \mathrm{Br}_{18}$ a strong association existed between the $6 P g d-1$ genotype and the sex phenotype. The combined reciprocal crosses (between which no differences could be found) segregated as shown in table 5 .

Table 5 The numbers of sex phenotypes for each $6 P g d-1$ genotype class in the $\mathrm{F}_{1}$ of $\mathrm{Br}_{12} \times \mathrm{Br}_{18}$

\begin{tabular}{rrrrrr}
\hline & & H & IN & MS & Totals \\
\hline 6 Pgd-1 & NN & 17 & 20 & 24 & 61 \\
& SN & 43 & 26 & 2 & 71 \\
& SS & 1 & 0 & 0 & 1 \\
\cline { 3 - 5 } & & -61 & $-\overline{46}$ & -26 & $\overline{133}$ \\
\hline
\end{tabular}

Because $6 P g d-1$ is linked with the $S I$-locus ( $r=6.4$ per cent), an involved male sterility locus will be linked with the $S I$-locus too. The simplest model to explain the male sterile frequencies assumes two loci: $m r_{1}$ with sterility alleles linked with the $6 P g d-1^{\mathrm{N}}$ alleles in both parents, and a second locus $m r_{x}$ or $M r_{\mathrm{x}}$, not linked with $6 P g d-1$, which reduces the MS fraction by a factor 2 . Because $\mathrm{Br}_{12}$ is assumed to be genetically $\mathrm{IN}, \mathrm{Br}_{12}$ is $m r_{\mathrm{x}}^{\mathrm{mm}}$ or $M r_{\mathrm{x}}^{\mathrm{M}+}$, whereas $\mathrm{Br}_{18}$ is $m r_{\mathrm{x}}^{\mathrm{m}+}$ or $M r_{\mathrm{x}}^{++}$. The parental chromosomes for linkage group $\mathrm{V}$ are:

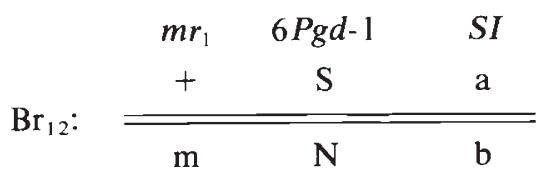

and

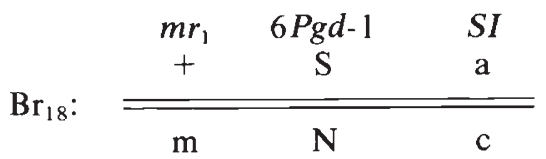

with the remark that the sequence of $S I$ and $6 P g d-1$ is still uncertain. In the progeny the $m r_{1}^{\mathrm{mm}}$ fraction is given by $(1-r) / 2, r$ being the recombination frequency between $m r_{1}$ and $S I$. The other locus $m r_{\mathrm{x}}$ (or $M r_{\mathrm{x}}$ ) reduces the number of male steriles to $(1-r) / 4$. The 19.5 per cent MS observed corresponds to an $r$-value of 22 per cent. In this model the fraction of IN genotypes is $\frac{1}{2}-\frac{1}{4} r$ which gives an expectancy of 59 IN's. Because only 46 IN phenotypes are observed, about 22 per cent of the IN genotypes would be phenotypically $H$, assuming perfect segregation ratios. Using this model a recombination percentage of 13.4 (5.9$23.7)$ could be calculated between $m r_{1}$ and $6 P g d-1$ (see Appendix B).

A still more complicated situation was met in the crosses between $F_{1}$ plants of the cross $\mathrm{He}_{88} \times$ $\mathrm{We}_{44}$. A significant association between sex phenotype and enzyme genotype was established here with $6 P g d-3, T o-2$ and $P g m-2$, so two different linkage groups (III and IV, see table 4) are involved. For these linkage groups identical chromosomes were concerned in the four $F_{1}$ crosses scored for sex phenotype (see table 3), which allows the combination of their progenies for this purpose. The linkage relations between sex phenotype and the enzyme genotype were indeed found to be similar in all these progenies, although individually not always statistically significant due to the low numbers in each separate cross. The combined numbers of MS, IN and $\mathrm{H}$ plants in each of the $6 \mathrm{Pgd}-3 / \mathrm{To}-2$ genotype classes are shown in table 6 . The $6 P g d-3^{\mathrm{NF}}$ plants could be divided into two classes by making use of the linked Got-2 locus, one class containing the $6 P g d-3^{\mathrm{F}}$ allele derived from $\mathrm{He}_{88}$ and the other class with the $6 P g d-3^{\mathrm{F}}$ allele from $\mathrm{We}_{44}$. In $T o-2$ both Falleles were from $\mathrm{He}_{88}$ origin, both $\mathrm{N}$ alleles from $\mathrm{We}_{44}$ origin.

The simplest model to explain the results is the assumption of a dominant gene $\mathrm{Mr}_{3}$ linked with $6 P g d-3$ and a recessive gene $m r_{2}$ linked with $T o-2$. The parental genotypes are (considering that $\mathrm{He}_{88}$ is IN-c):

\begin{tabular}{|c|c|c|c|c|c|c|}
\hline \multirow{3}{*}{$\mathrm{He}_{88}$ : } & $\mathrm{Mr}_{3}$ & $6 P g d-3$ & Got-2 & $m r_{2}$ & To-2 & Pgm-2 \\
\hline & $\mathrm{M}$ & $F$ & $S$ & $\mathrm{~m}$ & $F$ & $\mathrm{~N}$ \\
\hline & + & $\mathrm{N}$ & $\mathrm{F}$ & + & $\mathrm{N}$ & $\mathrm{N}$ \\
\hline \multirow{2}{*}{$e_{44}$} & + & $\mathrm{F}$ & $S$ & + & $F$ & $\mathrm{~N}$ \\
\hline & + & $\mathrm{N}$ & $\mathrm{S}$ & + & $\mathrm{N}$ & $S_{2}$ \\
\hline
\end{tabular}

and the two genotypes of the $F_{1}$ plants used as parents for the $F_{2}$ are:

\begin{tabular}{|c|c|c|c|c|c|}
\hline+ & $\mathrm{F}$ & $\mathrm{S}$ & $\mathrm{m}$ & $\mathrm{F}$ & $\mathrm{n}$ \\
\hline+ & $\mathrm{N}$ & $\mathrm{F}$ & + & $\mathbf{N}$ & $S_{2}(N)$ \\
\hline
\end{tabular}

and

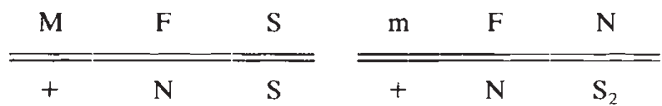


Table 6 The numbers of MS-IN-H plants for each $6 P g d-3 / T o-2$ genotype in the combined $\mathrm{F}_{2}$ 's from $\mathrm{He}_{88} \times \mathrm{We}_{44}$

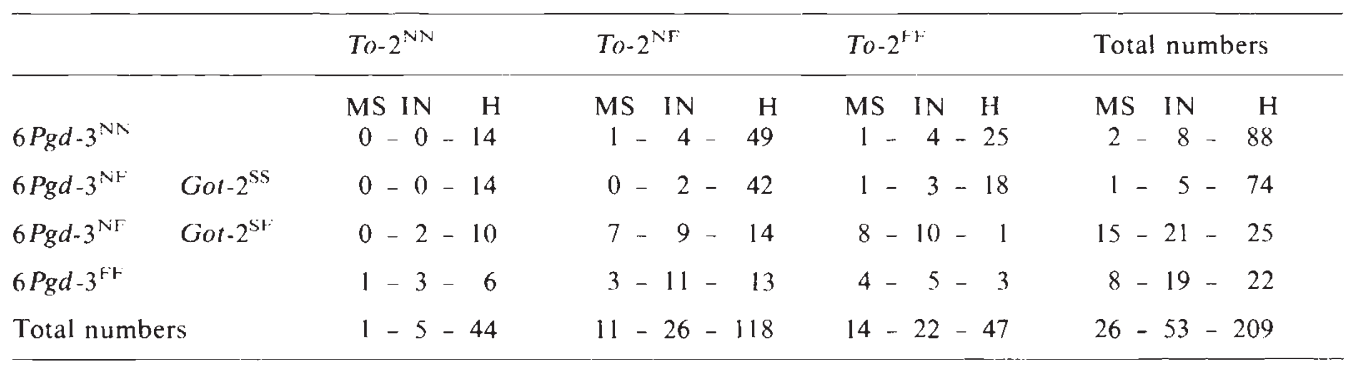

with the restriction that the sequences in both linkage groups are not absolutely certain, although the lack of any linkage effects between sex phenotype and Lap- 2 or Est-4 makes the alternative sequences unlikely.

The recombination percentage between $\mathrm{Mr}_{3}$ and $6 P g d-3$ can be calculated as $11.9(5 \cdot 9-19 \cdot 8)$, taking into account the disturbing influence on the division of $6 P g d-3$ genotypes by the use of the Got-2 locus, which showed about 6 per cent recombination with $6 P g d-3$. In Appendix $B$ the detailed calculation of the recombination percentage is given. It is not possible to detect any recombination between $\mathrm{Mr}_{3}$ and Got-2 in these crosses because no combined heterozygotes were involved. From table 6 it can be concluded that no IN's appear when the $M r_{3}$ locus is in the ++ state. The few IN's still observed in the two upper rows can fully be explained by the recombination between $\mathrm{Mr}_{3}$ and $6 \mathrm{Pgd}-3$.

In the other linkage group (III) the recombination percentages of $\mathrm{mr}_{2}$ with both To-2 and Pgm-2 could be calculated as $32 \cdot 2$ per cent $(24 \cdot 4-41 \cdot 6)$ between $\mathrm{mr}_{2}$ and To-2 (see Appendix B) and 33.4 per cent (24.4-44.8) between $m r_{2}$ and $P g m-2$. The observed number of IN plants was almost in agreement with the expected number of $\mathrm{mr}_{2}^{\mathrm{m}+}, \mathrm{Mr}_{3}^{\mathrm{M}+}$. The expression of this genotype appeared to be 85 per cent $\mathrm{IN}$ and 15 per cent $\mathrm{H}$.
The above made assumptions about the inheritance of male sterility in the $\mathrm{F}_{2}$ of $\mathrm{He}_{88} \times \mathrm{We}_{44}$ are consistent with the absence of MS plants in the $F_{1}$ (see table 3 ). This $F_{1}$ contained, however, 63 plants with an enzyme genotype predicting an IN genotype. To explain the only 4 plants showing the IN phenotype an expression of 6 per cent IN and 94 per cent $\mathrm{H}$ in the IN genotype has to be assumed.

\section{Germination}

A variable fraction of the seeds produced in each cross germinated spontaneously under the conditions used (table 3). Germination is a character which is very susceptible to environmental conditions, in particular humidity. Alternation of wet and dry periods enlarge the germination fraction, and the germination increases also with longer periods of storage after ripening (Blom, 1978). Because of the strong influence of germination conditions, no conclusions will be drawn from the differences in germination percentages, ranging from 21 to 86 . When however within one cross, of which the seeds have always been germinated in the same petri dish, significant differences in germination behaviour between the enzymes genotypes could be established, genetic variation is made probable.

Table 7 Significance levels of the relations between germination behaviour and enzyme genotype $(-P>0.05, * P<0.05$, ** $P<0.01, * * * P<0.001)$

\begin{tabular}{llccc}
\hline Linkage group & $\begin{array}{l}\text { Crosses } \\
\mathrm{Br}_{12} \times \mathrm{Br}_{18}\end{array}$ & $\mathrm{Br}_{23} \times \mathrm{Br}_{72}$ & $\mathrm{He}_{88} \times \mathrm{We}_{44}$ & $\mathrm{~F}_{1} \times \mathrm{F}_{1} \mathrm{He}_{88} \times \mathrm{We}_{44}$ \\
\hline I (Gpi-1, Lap-1) & - & - & $* *$ & - \\
II $($ Got -1, Idh, Est-5) & - & $* * *$ & $* * *$ & $* * *$ \\
III $($ To-2, Pgm-2, Est-4) & - & - & - \\
IV $(6$ Pgd-3, Got-2, Lap-2) & & - & $*$ & $*$ \\
V $(6$ Pgd-1, 6Pgd-2, Pgm-1) & $*$ & - & - & $*$ \\
\hline
\end{tabular}


Such differences between enzyme genotypes were found to some extent in all crosses. A survey of the differences (table 7) shows a strong effect of linkage group II in crosses with plants from different origin, and also linkage group $\mathrm{V}$ shows an effect in different crosses, although much weaker. The distinctly significant effect of linkage group I in the cross $\mathrm{He}_{88} \times \mathrm{We}_{44}$ was not repeated in the $F_{1} \times F_{1}$ crosses, but this can be explained by regarding the $F_{1}$ plants chosen: in each of those crosses the same linkage group I chromosome from $\mathrm{He}_{88}$ origin was present in both parents, whereas the different influence on germination behaviour in the $F_{1}$ was due to a difference between both $\mathrm{He}_{88}$ chromosomes. By similar considerations linkage group II and linkage group V chromosomes could be divided into those with relatively strong and those with less strong effects on spontaneous germination. Not shown here is that within linkage group I, Gpi-1 acted more strongly on germination than Lap-1; within linkage group II the effects of $I d h$ and Est-5 were stronger than the effect of Got-1.

\section{DISCUSSION}

The original aim of analysing crosses of P. lanceolata: verifying the Mendelian inheritance of the enzyme loci and grouping them on chromosomes, has been achieved satisfactorily. The five concluded linkage groups may well correspond to five different chromosomes although the possibility of two linkage groups on the same chromosome cannot be totally excluded. Like this 6 Pgd-3 and Lap-2 would not have been placed in the same linkage group without the interjacent Got-2 locus which is linked with both other loci. Also the linkage between Est-4 and To- 2 would have been questionable without the presence of the intermediate Pgm2 locus. The estimates of the recombination frequencies presented are not only of limited accuracy due to sampling effects, but may also be influenced by genetic variation in recombination. Because recombination frequencies have been reported to be different in oogenesis and spermatogenesis in several plant species (see Bell, 1982), the values determined may be considered to represent mean recombination frequencies for both sexes.

A lot of additional information has been obtained during these investigations. The important SI locus, controlling self-incompatibility, could be placed in one of the linkage groups. The tight linkage with $P g m-1$ provides the possibility of "labelling" $S I$ alleles by means of Pgm-1 alleles, avoiding in this way elaborate incompatibility tests. The $6 P g d-1$ and -2 loci, although less closely linked, may also be useful for such purposes.

Three male sterility loci have been placed in three different linkage groups. To explain the segregating numbers of male steriles and intermediates, assumptions about the inheritance of male sterility made by Van Damme (1983b) appeared to be very useful. In his model a male sterile phenotype will arise when the multi-locus genotype is at least $m r_{1}^{\mathrm{mm}}, \mathrm{mr}_{2}^{\mathrm{mm}}, \mathrm{Mr}_{3}^{\mathrm{M}+}, \mathrm{Mr}_{4}^{\mathrm{M}+}$, $\mathrm{Mr}_{5}^{\mathrm{M}+}$. When one $\mathrm{m}$-allele is missing the phenotype will be IN. The possibility that instead of one $m$-allele, one $M$-allele could be missed still resulting in an IN phenotype is not in agreement with the behaviour of the locus $\mathrm{Mr}_{3}$ in this study.

Considering only the male sterility loci noticed in the particular crosses, the most probable parental genotypes are: $\mathrm{Br}_{12}=m r_{1}^{\mathrm{m}+}, m r_{\mathrm{x}}^{\mathrm{mm}} ; \mathrm{Br}_{18}=m r_{1}^{\mathrm{m}+}$, $m r_{\mathrm{x}}^{\mathrm{m}+} ; \mathrm{He}_{88}=m r_{2}^{\mathrm{m}+}, M r_{3}^{\mathrm{M}+} ; \mathrm{We}_{44}=m r_{2}^{++}, M r_{3}^{++}$. The numbers of MS plants in the various progenies are in full agreement with the model, and so are the parental phenotypes. The IN frequencies however are always lower than predicted. It was calculated that the genotypes $m r_{1}^{\mathrm{mm}}, m r_{\mathrm{x}}^{\mathrm{m}+}$ and $m r_{1}^{\mathrm{m}+}, m r_{\mathrm{x}}^{\mathrm{mm}}$ in the cross $\mathrm{Br}_{12} \times \mathrm{Br}_{18}$ gave rise to only 78 per cent IN while 22 per cent was $H$. In the crosses $\mathrm{He}_{88} \times \mathrm{We}_{44}$ the genotype $\mathrm{mr}_{2}^{\mathrm{m}+}, \mathrm{Mr}_{3}^{\mathrm{M}+}$ resulted in 6 per cent IN and 94 per cent $\mathrm{H}$ in the $F_{1}$ and in 85 per cent $I N$ and 15 per cent $H$ in the $F_{2}$. Especially this difference between $F_{1}$ and $F_{2}$ with the same variable male sterility loci involved, and scored for sex phenotype under exactly the same environmental conditions, suggests that additional loci exist which modify the fraction of IN expressed in the IN genotype.

As these experiments were not primarily set up to analyse male sterility, some questions still remain. So it is unclear whether $m r_{\mathrm{x}}$ is indeed a recessive gene and whether it is identical to $m r_{2}$. The cross $\mathrm{Br}_{12} \times \mathrm{Br}_{18}$ could have answered this question when many more offspring were studied: $P g m-2$ is segregating too and a double heterozygote $m r_{\mathrm{x}}^{\mathrm{m+}}, P g m-2^{\mathrm{NF}_{2}}$ is involved. With the numbers used, however, the results were compatible with both $m r_{\mathrm{x}}=m r_{2}$ and $m r_{\mathrm{x}} \neq m r_{2}$ although somewhat closer to the first possibility. Furthermore two male sterility loci are not met in the crosses at all: $M r_{4}$ and $M r_{5}$. A series of experiments adjusted to the problem would undoubtedly bring about a more complete knowledge of the genetic basis of male sterility in P. lanceolata. The merit of the use of allozyme marker loci exists in making male sterility loci with similar effects distinguishable which makes it possible to study them separately. 
Because the aim is a further use of allozyme variation in studying the genetics of ecological differences, the effects of certain linkage groups on germination behaviour as found here are interesting. In nature germination in P. lanceolata is observed to occur largely during spring in most vegetation types whereas germination in autumn is predominant in some very dense vegetations (Van der Toorn, unpublished). Whether this difference is genetically determined is not known thus far. If so, the genetic factors determining this difference are not necessarily the same as the loci responsible for the observed germination differences in the petri dishes. Nevertheless, the conclusion that the existing ecological differences within the species $P$. lanceolata can be analysed in a successful way by making use of allozyme variation seems to be correct. When compared with $P$. major (Van Dijk, 1984) such an analysis will be more difficult because of the larger intrapopulational genetic variability of $P$. lanceolata, but the greater number of variable enzyme loci allows a good ultimate result.

Acknowledgements I am very grateful to Kirsten Wolff who collected the plants, determined their genotypes, and provided me with suitable plants for making crosses.

I would like to thank Mr P. Dubbeldam and Miss C. ter Horst for technical assistance and Drs J. van Damme, W. van Delden and G. van Nigtevecht for critically reading earlier drafts of the manuscript.

These investigations were supported by the Foundation for Fundamental Biological Research (BION), which is subsidised by the Netherlands Organisation for the Advancement of Pure Research (ZWO).

\section{APPENDIX A}

\section{The calculation of recombination frequencies}

The observed numbers of each possible two-locus genotype (see table $8(\mathrm{a})$ ) or enzyme genotype/sex phenotype combinations are compared with the expected numbers belonging to the segregation model chosen and being a function of the recombination frequency $r$ (table $8(\mathrm{c}))$. With the aid of a computer the value of $r$ which gives the minimal $\chi^{2}$ value is easily found, together with the 95 per cent confidence interval which includes all $r$ 's leading to a $\chi^{2}$ less than $\chi_{\min }^{2}+3 \cdot 84$. An approvement of this method is attained when the observed genotype numbers are previously corrected in order to obtain row and column totals which are in accordance with the expected segregation ratios (table $8(\mathrm{~b})$ ). This correction is possible without disturbing any deviations caused by the eventual linkage: alternately the genotype numbers are changed to obtain correct row totals and to obtain correct column totals. This iterative process is stopped when no further change is observed. Disturbing influences other than those originating from linkage are removed partially in this way.

If the $\chi^{2}$ value, with the remaining degrees of freedom, is not significant at the 5 per cent level for $r=0 \cdot 5$, linkage is assumed to be absent unless there is other evidence for its existence e.g., when data for a third locus, linked with the ones under study, are available. The minimal $\chi^{2}$ value gives information about the relative probability of the segregation model used, which is of particular importance in cases where different male sterility

Table 8 A worked example of the calculation of recombination frequencies

\begin{tabular}{|c|c|c|c|c|c|c|c|c|c|}
\hline \multicolumn{6}{|c|}{ a. Observed numbers } & \multicolumn{4}{|c|}{ b. Corrected numbers } \\
\hline & & $\begin{array}{l}6 P g d-3 \\
\text { NN }\end{array}$ & NF & $\mathrm{FF}$ & Totals & NN & NF & FF & Totals \\
\hline \multirow[t]{3}{*}{ Got-2 } & SS & 10 & 212 & 129 & 351 & $6 \cdot 8$ & $190 \cdot 9$ & $168 \cdot 9$ & $366 \cdot 6$ \\
\hline & $\mathrm{SF}$ & 213 & 160 & 9 & 382 & $176 \cdot 5$ & $175 \cdot 7$ & $14 \cdot 4$ & $366 \cdot 6$ \\
\hline & & 223 & 372 & 138 & $\overline{733}$ & $\overline{183 \cdot 3}$ & $\overline{366 \cdot 6}$ & $\overline{183 \cdot 3}$ & $\overline{733 \cdot 2}$ \\
\hline
\end{tabular}

c. Expected numbers

\begin{tabular}{lllll} 
& $\mathrm{NN}$ & $\mathrm{NF}$ & $\mathrm{FF}$ & Totals \\
$\mathrm{SS}$ & $\frac{1}{4} r N$ & $\frac{1}{4} N$ & $\frac{1}{4}(1-r) N$ & $\frac{1}{2} N$ \\
$\mathrm{SF}$ & $\frac{1}{4}(1-r) N$ & $\frac{1}{4} N$ & $\frac{1}{4} r N$ & $\frac{1}{2} N$ \\
\hline & $\frac{4}{\frac{1}{4} N}$ & $\frac{1}{\frac{1}{2} N}$ & $\frac{1}{\frac{1}{4} N}$ & $\frac{2}{N}$
\end{tabular}


inheritance models are possible. When the same linkage relationship is studied in crosses producing different segregation ratios, the results are combined by reducing the more complex ratios to the most simple ratio e.g., $1: 1: 1: 1$ to $1: 2: 1$ or $1: 2: 1$ to $1: 1$. As this is only a matter of making different alleles indistinguishable by giving them the same name, the recombination frequencies calculated will not be affected. The confidence intervals will be broadened, however, because some information is lost.

The correctness of the described method of calculating recombination frequencies and confidence intervals has been checked by computer simulation. The worked example in table 8 is based on the real data of the crosses made. The minimal $\chi_{(1)}^{2}$, applied on the figures of table $8(\mathrm{~b})$, is 3.45 at $r=6 \cdot 1$ per cent. The $\chi^{2}=7 \cdot 29$ at $r=4 \cdot 1$ per cent and at $r=9 \cdot 0$ per cent. The maximum likelihood method (see Green, 1981) would give here $5 \cdot 8$ per cent $(3 \cdot 4-8 \cdot 2)$, also applied on the corrected numbers. only, because the expected numbers of $6 \mathrm{Pgd}$ $1^{\text {SS }} / \mathrm{MS}$ or IN are too low. Table 9 gives a survey of the procedure to calculate the expected numbers in each class. The 6.4 per cent recombination between $6 P g d-1$ and $S I$, and the assumed 78 per cent expression of the IN genotype have been taken into account.

The minimal $\chi_{(3)}^{2}=1.77$ at $r=13.4$ per cent. The $\chi^{2}$ value is 5.61 at $r=5.9$ per cent and at $r=23 \cdot 7$ per cent.

\section{$\mathrm{Mr}_{3}$ and $6 \mathrm{Pgd}-3$.}

The calculation of the expected numbers is given in table 10 , taking into account the 6.1 per cent recombination between $6 \mathrm{Pgd}-3$ and Got-2 and the assumed 85 per cent expression of the IN genotype. The observed numbers, as shown in table 6 , have to be corrected for unequal row and column totals. Because $6 \mathrm{Pgd}-3$ and $T o-2$ are not linked to each other, the expected frequency of each two-locus enzyme genotype is equal to the product of the

Table 9 Recombination frequency between $m r_{1}$ and $6 P g d-1$ : survey of calculation steps

a. Expected gamete frequencies (double crossing overs neglected)

\begin{tabular}{|c|c|c|c|}
\hline $\begin{array}{l}m r_{1}^{\mathrm{m}} / 6 P g d-1^{\mathrm{N}} \\
m r_{1}^{+} / 6 P g d-1^{\mathrm{N}} \\
m r_{1}^{\mathrm{m}} / 6 P g d-1^{\mathrm{s}} \\
m r_{1}^{+} / 6 P g d-1^{\mathrm{s}}\end{array}$ & $\begin{array}{l}\text { Pollen } \\
\text { M1 }=0.936(1-r) \\
\text { M2 }=0.936 r \\
\quad 0 \\
\text { M3 }=0.064\end{array}$ & \multicolumn{2}{|l|}{$\begin{array}{l}\text { Ovuli } \\
\text { F1 }=0 \cdot 5-0.468 r \\
\text { F2 }=0.468 r \\
\text { F3 }=0.468 r \\
\text { F4 }=0.5-0.468 r\end{array}$} \\
\hline \multicolumn{2}{|c|}{$\begin{array}{l}\text { b. Expected } m r_{1} / 6 P g d-1 \text { genotype frequencies } \\
\mathrm{mm} / \mathrm{NN}: \mathrm{G} 1=\mathrm{M} 1 \mathrm{~F} 1 \\
\mathrm{~m}+/ \mathrm{NN}: \mathrm{G} 2=\mathrm{M} 1 \mathrm{~F} 2+\mathrm{M} 2 \mathrm{~F} 1 \\
++/ \mathrm{NN}: \mathrm{G} 3=\mathrm{M} 2 \mathrm{~F} 2 \\
\mathrm{~mm} / \mathrm{SN}: \mathrm{G} 4=\mathrm{M} 1 \mathrm{~F} 3 \\
\mathrm{~m}+/ \mathrm{SN}: \mathrm{G} 5=\mathrm{M} 1 \mathrm{~F} 4+\mathrm{M} 2 \mathrm{~F} 3+\mathrm{M} 3 \mathrm{~F} 1 \\
++/ \mathrm{SN}: \mathrm{G} 6=\mathrm{M} 2 \mathrm{~F} 4+\mathrm{M} 3 \mathrm{~F} 2\end{array}$} & \multicolumn{2}{|c|}{$\begin{array}{l}\text { c. Expected phenotype frequencies } \\
\text { MS/NN: } \mathrm{P} 1=\frac{1}{2} \mathrm{G} 1 \\
\mathrm{IN} / \mathrm{NN}: \mathrm{P} 2=0 \cdot 78\left(\frac{1}{2} \mathrm{G} 1+\frac{1}{2} \mathrm{G} 2\right) \\
\mathrm{H} / \mathrm{NN}: \mathrm{P} 3=0 \cdot 22\left(\frac{1}{2} \mathrm{G} 1+\frac{1}{2} \mathrm{G} 2\right)+\frac{1}{2} \mathrm{G} 2+\mathrm{G} 3 \\
\mathrm{MS} / \mathrm{SN}: \mathrm{P} 4=\frac{1}{2} \mathrm{G} 4 \\
\mathrm{IN} / \mathrm{SN}: \mathrm{P} 5=0 \cdot 78\left(\frac{1}{2} \mathrm{G} 4+\frac{1}{2} \mathrm{G} 5\right) \\
\mathrm{H} / \mathrm{SN}: \mathrm{P} 6=0 \cdot 22\left(\frac{1}{2} \mathrm{G} 4+\frac{1}{2} \mathrm{G} 5\right)+\frac{1}{2} \mathrm{G} 5+\mathrm{G} 6\end{array}$} \\
\hline $\begin{array}{l}\text { d. Phenotype numbers } \\
\text { MS/NN } \\
\text { IN/NN } \\
\text { H/NN } \\
\text { MS/SN } \\
\text { IN/SN } \\
\text { H/SN }\end{array}$ & $\begin{array}{l}\text { Expected } \\
\mathrm{P} 1 \times 61 /(\mathrm{P} 1+\mathrm{P} 2+\mathrm{P} 3) \\
\mathrm{P} 2 \times 61 /(\mathrm{P} 1+\mathrm{P} 2+\mathrm{P} 3) \\
\mathrm{P} 3 \times 61 /(\mathrm{P} 1+\mathrm{P} 2+\mathrm{P} 3) \\
\mathrm{P} 4 \times 71 /(\mathrm{P} 4+\mathrm{P} 5+\mathrm{P} 6) \\
\mathrm{P} 5 \times 71 /(\mathrm{P} 4+\mathrm{P} 5+\mathrm{P} 6) \\
\mathrm{P} 6 \times 71 /(\mathrm{P} 4+\mathrm{P} 5+\mathrm{P} 6)\end{array}$ & $\begin{array}{l}\text { Expected at } r=13 \cdot 4 \text { per cent } \\
23 \cdot 1 \\
23 \cdot 4 \\
14 \cdot 5 \\
3 \cdot 6 \\
24 \cdot 4 \\
43 \cdot 0\end{array}$ & $\begin{array}{l}\text { Observed } \\
24 \\
20 \\
17 \\
2 \\
26 \\
43\end{array}$ \\
\hline
\end{tabular}

\section{APPENDIX B}

The calculation procedures of the recombination frequencies between allozyme loci and male sterility loci.

$m r_{1}$ and $6 P g d-1$

The data are given in table 5. The $\chi^{2}$ is calculated from the $6 P g d-1 \mathrm{NN}$ and $\mathrm{SN}$ genotype numbers expected single-locus genotype frequencies.

The minimal $\chi_{(3)}^{2}=2.60$ at $r=11.9$ per cent. The $\chi^{2}$ value is 6.44 at $r=5.9$ per cent and at $r=19 \cdot 8$ per cent.

$m r_{2}$ and To-2.

Table 11 shows the calculation procedure of the expected numbers, assuming 85 per cent 
Table 10 Recombination frequency between $\mathrm{Mr}_{3}$ and $6 \mathrm{Pgd}-3$ : survey of calculation steps

a. Expected gamete frequencies

$\begin{array}{lll} & \text { First parent (F from He) } & \text { Second parent (F from We }) \\ M r_{3}^{\mathrm{M}} / 6 P g d-3^{\mathrm{F}} & 3 & - \\ \mathrm{Mr}_{3}^{\mathrm{M}} / 6 \mathrm{Pgd}-3^{\mathrm{N}} & \frac{1}{2} r & - \\ \mathrm{Mr}_{3}^{+} / 6 P g d-3^{\mathrm{N}} & \frac{1}{2} r & \frac{1}{2} \\ \mathrm{Mr}_{3}^{+} / 6 P g d-3^{\mathrm{N}} & \frac{1}{2}(1-r) & \frac{1}{2}\end{array}$

b. Expected $\mathrm{Mr}_{3} / 6 \mathrm{Pgd}-3$ genotype frequencies

$\mathrm{M}+/ \mathrm{FF}$ or $\mathrm{NF}(\mathrm{F}$ from $\mathrm{He}): \mathrm{Gl}=\frac{1}{2}(1-r)$

$\mathrm{M}+/ \mathrm{NN}$ or $\mathrm{NF}\left(\mathrm{F}\right.$ from We): $\mathrm{G} 2=\frac{1}{2} r$

$++/ \mathrm{FF}$ or $\mathrm{NF}(\mathrm{F}$ from $\mathrm{He}): \mathrm{G} 3=\frac{1}{2} r$

$++/ \mathrm{NN}$ or NF (F from We): $\mathrm{G} 4=\frac{1}{2}(1-r)$

c. Expected phenotype frequencies
$\mathrm{MS} / \mathrm{FF}$ or NF ( $\mathrm{F}$ from $\mathrm{He}$ ):
IN/FF or NF (F from $\mathrm{He}$ ):
$\mathrm{H} / \mathrm{FF}$ or $\mathrm{NF}$ (F from $\mathrm{He}$ ):
$\mathrm{MS} / \mathrm{NN}$ or NF (F from We)
IN/NN or NF (F from We):
$\mathrm{Pl}=\frac{1}{4} \mathrm{Gl}$
$\mathrm{P} 2=0.85 \times \frac{1}{2} \mathrm{G} 1$
$\mathrm{P} 3=0 \cdot 15 \times \frac{1}{2} \mathrm{G} 1+\frac{1}{4} \mathrm{G} 1+\mathrm{G} 3$
$\mathrm{P} 4=\frac{1}{4} \mathrm{G} 2$
$\mathrm{P} 5=0.85 \times \frac{1}{2} \mathrm{G} 2$
$\mathrm{H} / \mathrm{NN}$ or $\mathrm{NF}$ ( $F$ from We):
$\mathrm{P} 6=0 \cdot 15 \times \frac{1}{2} \mathrm{G} 2+\frac{1}{4} \mathrm{G} 2+\mathrm{G} 4$

d. Phenotype numbers

$\mathrm{MS} / \mathrm{FF}$ or NF (Got-2 SF)

Expected

IN/FF or NF (Got-2 SF)

$\mathrm{H} / \mathrm{FF}$ or NF (Got-2 SF)

MS/NN or NF (Got-2 SS)

IN/NN or NF (Got-2 SS)

$\mathrm{H} / \mathrm{NN}$ or NF (Got-2 SS)

$(0.9695 \mathrm{P} 1+0.0305 \mathrm{P} 4) 288$

$(0.9695 \mathrm{P} 2+0.0305 \mathrm{P} 5) 288$

$(0.9695 \mathrm{P} 3+0.0305 \mathrm{P} 6) 288$

$(0.0305 \mathrm{Pl}+0.9695 \mathrm{P} 4) 288$

$(0.0305 \mathrm{P} 2+0.9695 \mathrm{P} 5) 288$

$(0 \cdot 0305 \mathrm{P} 3+0.9695 \mathrm{P} 6) 288$
Exp. at

$\begin{array}{cc}r=11 \cdot 9 & \begin{array}{l}\text { Observed } \\ \text { per cent }\end{array} \\ 30 \cdot 9 & 27 \cdot 8 \\ 52 \cdot 5 & 50 \cdot 8 \\ 60 \cdot 6 & 65 \cdot 4 \\ 5 \cdot 1 & 2 \cdot 1 \\ 8 \cdot 7 & 9 \cdot 2 \\ 130 \cdot 2 & 132 \cdot 7\end{array}$

Table 11 Recombination frequency between $m r_{2}$ and To-2: survey of calculation steps

a. Expected gamete frequencies in both parents

$\begin{array}{ll}m r_{2}^{m} / T o-2^{\mathrm{F}}: & \mathrm{H} 1=\frac{1}{2}(1-r) \\ m r_{2}^{\mathrm{m}} / T_{0}-2^{\mathrm{N}}: & \mathrm{H} 2=\frac{1}{2} r \\ m r_{2}^{+} / \text {To- } 2^{\mathrm{F}:}: & \mathrm{H} 3=\frac{1}{2} r \\ m r_{2}^{+} / \text {To- }^{\mathrm{N}}: & \mathrm{H} 4=\frac{1}{2}(1-r) \\ \text { b. Expected } & m r_{2} / \text { To-2 } \text { genotype }\end{array}$

b. Expected
frequencies

$\mathrm{mm} / \mathrm{FF}$ :

$\mathrm{mm} / \mathrm{NF}$ :

$\mathrm{mm} / \mathrm{NN}$ :

$\mathrm{m}+/ \mathrm{FF}$ :

$\mathrm{m}+/ \mathrm{NF}$ :

$\mathrm{m}+/ \mathrm{NN}$ :

$++/ \mathrm{FF}:$

$++/ \mathrm{NF}$ :

$++/ \mathrm{NN}$ :

$\mathrm{G} 1=\mathrm{H}^{2}$

$\mathrm{G} 2=2 \mathrm{H} 1 \mathrm{H} 2$

$\mathrm{G} 3=\mathrm{H}^{2}$

$\mathrm{G} 4=2 \mathrm{H} 1 \mathrm{H} 3$

$\mathrm{G} 5=2 \mathrm{H} 1 \mathrm{H} 4+2 \mathrm{H} 2 \mathrm{H} 3$

$\mathrm{G} 6=2 \mathrm{H} 2 \mathrm{H} 4$

$\mathrm{G} 7=\mathrm{H}^{2}$

$\mathrm{G} 8=2 \mathrm{H} 3 \mathrm{H} 4$

c. Expected phenotype frequencies

d. Phenotype numbers

\begin{tabular}{|c|c|c|c|}
\hline & Expected & Expected at $r=32.2$ per cent & Observed (corrected) \\
\hline $\mathrm{MS} / \mathrm{FF}$ & $288 \mathrm{Pl}$ & $16 \cdot 5$ & $15 \cdot 0$ \\
\hline $\mathrm{IN} / \mathrm{FF}$ & $288 \mathrm{P} 2$ & $13 \cdot 4$ & $21 \cdot 8$ \\
\hline $\mathrm{H} / \mathrm{FF}$ & $288 \mathrm{P} 3$ & $42 \cdot 1$ & $35 \cdot 2$ \\
\hline $\mathrm{MS} / \mathrm{NF}$ & $288 \mathrm{P} 4$ & $15 \cdot 7$ & $13 \cdot 1$ \\
\hline IN/NF & $288 \mathrm{P} 5$ & $34 \cdot 5$ & $29 \cdot 8$ \\
\hline $\mathrm{H} / \mathrm{NF}$ & $288 \mathrm{P} 6$ & $93 \cdot 8$ & $101 \cdot 1$ \\
\hline $\mathrm{MS} / \mathrm{NN}$ & $288 \mathrm{P} 7$ & $3 \cdot 7$ & $1 \cdot 8$ \\
\hline IN/NN & $288 \mathrm{P} 8$ & $13 \cdot 4$ & $8 \cdot 4$ \\
\hline $\mathrm{H} / \mathrm{NN}$ & $288 \mathrm{P} 9$ & 54.9 & $61 \cdot 8$ \\
\hline
\end{tabular}


expression of the IN genotype. The observed numbers have been corrected as described above.

The minimal $\chi_{(5)}^{2}=12.02$ at $r=32.2$ per cent. The $\chi^{2}$ value is 15.86 at $r=24.4$ per cent and at $r=41.6$ per cent. The recombination frequency between $\mathrm{mr}_{2}$ and $\mathrm{Pgm}-2$ has been calculated in an analogous way (details not given).

\section{REFERENCES}

BELL, G. 1982. The masterpiece of nature. The evolution and genetics of sexuality. Croom Helm, London \& Canberra.

BLOM, C. W. P. M. 1978. Germination, seedling emergence and establishment of some Planiago species under laboratory and field conditions. Acra Bor. Neerl., 27, 257-271.

GREEN, E. L. 1981. Genetics and probability in animal breeding experiments. MacMillan Publ. Ltd. London.

PRIMACK, R. B. AND ANTONOVICS, J. 1981. Experimental ecological genetics in Plantago. V. Components of seed yield in the ribwort plantain Plantago lanceolata L. Evolution, $35,1069-1079$

ROSS, M. D. 1973. Inheritance of self-incompatibility in Planlago lanceolata. Heredity, 30, 169-176.
SAGAR, G. R. AND HARPER, J. L. 1964. Biological flora of the British Isles. Plantago major L., P. media L. and P. lanceo lata L. J. Ecol., 52, 189-221.

TERAMURA, A. H. AND STRAIN, B. R. 1979. Localized populational differences in the photosynthetic response to temperature and irradiation in Plantago lanceolata. Can. J. Bot., $57,2559-2563$.

VAN DAMmE, J. M. M. $1983 a$. On gynodioecy in Plantago lanceolata. Thesis. University of Groningen.

VAN DAMME, J. M. M. 1983 b. Gynodioecy in Plantago lanceolata L. II. Inheritance of three male sterility types. Heredity, 50, 253-273.

VAN DAMME, J. M. M. AND VAN DELDEN, W. 1982. Gynodioecy in Plantago lanceolata L. I. Polymorphism for plasmon type. Heredity, 49, 305-320.

VAN DIJK, H. 1984. Genetic variability in Plantago species in relation to their ecology. II. Quantitative characters and allozyme loci in P. major. Theor. Appl. Genet., 68, 43-52.

VAN DIJK, H. AND VAN DELDEN, W. 1981. Genetic variability in Plantago species in relation to their ecology. I. Genetic analysis of the allozyme variation in $P$. major subspecies. Theor. Appl. Genet., 60, 285-290.

VAN DIJK, H., WOLFF, K. AND DE VRIES, A. (in prep.). Genetic variability in Plantago species in relation to their ecology. III. Genetic structure of populations of $P$. major, $P$. lanceolata and $P$. coronopus. 